\title{
UN SINGULAR TIPO DE EXVOTO: LAS PEQUEÑAS FALCATAS
}

\author{
Pedro A. Lillo Carpio
}

Uno de los elementos más representativos del contexto cultural ibérico es, sin duda, la falcata. Los textos griegos y latinos reiteran la singularidad y efectividad de este elemento combativo que, en las guerras inmediatas a la conquista de la $\mathrm{Pe}$ nínsula por Roma es un arma especialmente constatada (1).

La falcata está presente en los conjuntos de la cultura ibérica y áreas con las que dicha cultura mantuvo contactos o influencias.

Los lugares usuales de hallazgo son los ajuares funerarios masculinos. A partir de estos ajuares se puede llegar a conclusiones, sobre todo de tipo porcentual. La presencia mayor o menor de falcatas en los contextos tumbales nos llevan a una serie de deducciones de las que cabría destacar:

- Es significativo que el porcentaje de falcatas sea mayor en las zonas que grosso modo marcan el limes con los pueblos de la Meseta como pone de relieve Nieto Gallo. Este hecho puede indicarnos un mayor índice de inseguridad ya que estas zonas están en contacto con áreas de menores posibilidades económicas y poblaciones proclives al saqueo (3).

- Es escaso el número de falcatas en las necrópolis de áreas sometidas a un prolongado proceso de aculturación. La zona litoral del sureste parece estar bajo el control del mercado mediterráneo púnico. Los pueblos prelitorales van a ser por lo general receptivos y con una economía relativamente ordenada, tanto al comercio interior como al comercio con los establecimientos de la costa.

- La necesidad del empleo de armas ofensivas y por tanto de la falcata se hace mayor donde hay riesgos de ataques y ocupaciones. Es necesaria la defensa de los

(1) Suidas, Fr. 96; Polibio, VI, 23, 6; Estrabón III, 3, 6 y III, 4, 15; Séneca, "De Benef» V, 24; San Isidoro, Etimolog. XVIII, 6, 7 y sobre todo Livio, Ab urbe condita, VIII, 9-1-11 hace referencia a las armas de los enemigos ofrecidas a Vulcano como norma. Diodoro, 23-25 y Floro 1, 3, 4, 3, hacen referencia a la extraordinaria consideración que tenían sus armas los iberos.

(2) Aquí podríamos tener en cuenta la idea ya apuntada por Dechelette al hablar de machaira, kopis y ondulé o epée d'Almedinilla al referirse a la falcata. El autor dice: "Mais en Grece les découvertes d'armes de l'époque classique sont rares, tandis que chez les peuples barbares l'habitude de les deposer 'ans les tombes nous en a conservé gran nombrem.

(3) Nieto Gallo, G.: "Coincidencias formales entre la machaira tracia y la falcata ibérica". Actes de Thracologie, III, Mallorca, 1981, Roma, 1982, pág. 98. 
pasos naturales que controlan estas vías de circulación. Para ello se ha de contar con mayor número de hombres armados - en muchos casos mercenarios procedentes de áreas más pobres - y sobre todo de armas efectivas. Entre estas armas, por su eficacia, la falcata es la pieza más importante del ajuar guerrero ibérico.

Factor fundamental para una determinada fase - desde el último cuarto del s. III a. C.- van a ser los acontecimientos bélicos de los que son protagonistas Escipiones y Bárcidas, Sertorio y Pompeyo, con una abundante presencia de armas, especialmente falcatas, en los poblados vinculados a los escenarios donde se armó a los ejércitos y tuvieron lugar los encuentros.

Es evidente que el área interior de la Región del Sureste, adentrándose en los límites de la Turdetania, según las Fuentes Antiguas y a la evidencia de los trabajos realizados al respecto, es para la época que nos ocupa una zona rica. A la proverbial abundancia en el conjunto agropecuario se suma el factor determinante de la minería. La zona Alto Guadalquivir Alto Segura es fundamental como cabecera de control del acceso desde el Mediterráneo a través de los valles levantinos. Por otra parte parece necesario considerar la zona como vinculada con la influencia púnica frente al comercio directo griego durante varias centurias. La tradicional defensa del Sureste sensu lato puede, pues, relacionarse con la abundante presencia de este tipo de armas. Es el área que ha dado ejemplares más bellos y con una cronología más amplia que cubre desde las piezas más antiguas (mediados del s. V) hasta época posterior a la conquista romana.

\section{Valor simbólico de la falcata}

Evidentemente la falcata es una adquisición excepcional en el ajuar guerrero no ya con respecto a las culturas peninsulares sino a nivel del mundo conocido. No sería aventurado, por tanto, considerar este arma como exponente de poder social, combatividad, valentía o dignidad viril, aún sin tener forzosamente que hacer alarde de estas virtudes castrenses mediante su uso en combate. Obviamente hemos de considerar también que ante la inexistencia de ejército o cuerpos de seguridad los pueblos han de vivir, aún en paz, permanentemente armados. Todo esto daría un especial sentido al arma, amén del funcional: símbolo de poder en la lucha. Es frecuente en la épica universal - y particularmente en la europea - la especial referencia a armas dotadas con poderes sobrenaturales, en especial espadas, poseedoras de mágicos vínculos con sus heroicos poseedores.

En esta línea de arma - símbolo o arma exponente máximo de la lucha- estaría su abundante representación en los exvotos de bronce del área ibérica meridional, donde es muy frecuente la representación del guerrero que empuña o lleva al cinto una falcata (4).

A nuestro juicio otro dato a tener en cuenta en contextos de necrópolis es la presencia de inhumaciones de falcatas solas, sin otro elemento de ajuar funerario 
y sin cadáver. Nieto Gallo excavó en la Necrópolis del Cabecico del Tesoro fosas exentas cuyo singular contexto era una falcata, lo que se podía interpretar como un acto oferente y simbólico. Cabe pensar que el rito de enterramiento del arma sustituya al del guerrero ausente, representando así la parte (falcata) al todo (guerrero desaparecido), es decir una personificación del arma (5).

\section{Las falcatas votivas}

Todo lo antedicho nos lleva a un intento de análisis de una serie de piezas, réplica a pequeña escala de la falcata. El contexto en que han aparecido los ejemplares que nos ocupan está especialmente vinculado con el mundo sobrenatural. En la necrópolis de Puig des Molins formaban parte de los ajuares funerarios (6). Tarradell y Font, al hacer referencia a estas piezas, pusieron de manifiesto la escasez de armas en las tumbas ebusitanas pero por su tamaño reducido las consideran como objetos rituales (7). Este carácter ritual es al que Nieto Gallo también hace referencia al comentar el verso 597 del canto XVIII de la Iliada (8). Exvotos de útiles y armas metálicas no han sido infrecuentes en yacimientos de tipo cultual, elementos que fueron representados en los reversos monetales con un alto contenido simbólico.

Al margen de las piezas halladas en Puig des Molins, conocidas por los estudiosos al menos desde 1923, nos hallamos con los conjuntos del sureste peninsular con peculiares características:

Los conjuntos de piezas conocidos proceden de áreas abiertas y con un claro valor de santuario:

- Santuario de la Luz (Murcia). Santuario ibérico inmediato a la Necrópolis del Cabecico del Tesoro y al poblado ibérico de Verdolay excavado por Mergelina Luna (9). La pieza y fragmentos conocidos aparecieron en superficie en la ladera.

- La Encarnación (Caravaca, Murcia). En este contexto arqueológico conocido por sus restos arquitectónicos romanos fueron halladas más de una treintena de piezas más o menos deterioradas, todas ellas de hierro y con un tamaño entre

(5) Agradecemos al Dr. Nieto Gallo la comunicación directa de estos datos por él registrados y hasta el momento inéditos. Sobre este tema hay datos sobre otras necrópolis: Blázquez, J. M.: «Panorama general de la presencia fenicio púnica en España». Consiglio della Ricerche, Roma, 1983, pág. 366. Hace referencia a unas urnas que estaban vacías pero que tenían ajuar lo que hace pensar que sean tumbas de gente cuyo cadáver no fue recuperado.

(6) Fernández, J. H.: «El hipogeo número 6 de la Campaña de 1923 en el Puig des Molins». Homenaje al Prof. Martín Almagro Basch, Madrid, 1983, n. 26 (fig. 7-4), lám. III-3.

(7) Tarradell, M. y Font, A.: Evissa Cartaginesa, Barcelona, 1975, fig. 83, págs. 209-211.

(8) Nieto Gallo, G.: Coincidencias formales... opus cit. Hace referencia al verso 597 del canto XVIII de la Iliada: "Las doncellas tenian maravillosas coronas y nuevas machairas de oro colgadas en plateados cinturones", lo que nos hace pensar que se trataría de pequeños modelos, hechos de oro, utilizados como adornos de forma análoga a cómo se utilizan actualmente esa serie de colgantes y bibelots a los que genéricamente, denominamos con el nombre de fetiches".

(9) Mergelina Luna, C.: "El Santuario hispánico de la Sierra de Murcia». Memoria de las excavaciones en el Eremitorio de Nuestra Sra. de la Luz. J. S. de Excavaciones y Ant. Memoria n. ${ }^{\circ}$ 7, Madrid, 1926, 19 p., 12 láms. 
3 y $9 \mathrm{~cm}$. de longitud; aparecieron dispersas, al parecer colocadas preferentemente entre las fisuras de las rocas - lapiaz calcáreo- intencionalmente colocadas (10). En la zona han aparecido fragmentos de figuritas votivas en bronce.

- Casas Viejas (Almaciles, Granada). Este yacimiento está en un afloramiento rocoso, igualmente calcáreo y en forma lapiaz de unos $30 \mathrm{~m}$. de longitud entre campos de labor. Unos $500 \mathrm{~m}$. al Norte está denominada la zona por un cerro amesetado de cuya cima debió de ser ocupada por un poblado de considerable importancia en el contexto turdetano, al menos hasta lás luchas con Escipión. Se observan considerables restos de escoria y fundición de hierro y plomo. En su vertiente meridional hay una fuente con restos cerámicos, en torno a la cual, según comunicación oral, han aparecido en distintas épocas figuritas de bronce o fragmentos de ellas. Tradicionalmente las gentes del lugar han venido hallando fragmentos de piezas completas de hierro entre 3 y $10 \mathrm{~cm}$. de longitud en el promontorio rocoso que hemos mencionado y en los campos de los alrededores del mismo. Estas laminitas, al igual que en el Santuario de la Encarnación, son en realidad reproducciones sumarias más o menos esquematizadas de falcatas. Su disposición, en algunos casos, es similar, estando encajadas en las fisuras de la roca.

\section{Descripción}

La índole del material del que están hechas la mayoría - hierro- pese a su buen estado relativo, al haber permanecido en superficie y entre piedras, ha deteriorado considerablemente las piezas conocidas hasta ahora. Todas ellas están hechas de una sola planchuela de metal batido por martilleado en caliente y por este mismo método se ha hecho en el extremo una espiga que, doblada, ha originado el enmangue.

La mayoría de las piezas conservan marcas del martilleado y sobre éste los retoques con lima, sobre la hoja especialmente. En algunos casos la conservación y buena factura de la pieza permite apreciar muestras de lijado y pulido en el arco del enmangue.

Sólo dos piezas son de bronce (fig. L1 y L4) que corresponden al tipo de cuchillitos afalcatados y una de plata (fig. H14) que pertenece al grupo más simple, correspondiente a las piezas que semejan agujas de hebilla de cinturón.

La falta de tratamiento de restauración del conjunto impide por el momento observar más detalles del proceso de fabricación así como la posible presencia, si los hubiera, de detalle de nivelado o damasquinado en algunas de las piezas si bien la elemental confección de las que nos ocupan nos hace pensar que no debieron de llevar decoración alguna. Dada la fragilidad y poca vistosidad de éstas, es posible que, reparando en ellas, este provisional conjunto se vea incrementado por piezas procedentes de excavaciones antiguas o depósitos de museos procedentes de prospecciones, lo que dará de este tipo de exvoto una visión más completa y contrastada.

(10) Nieto Gallo, G.: “Dos yacimientos arqueológicos en la Provincia de Murcia: El Cerro de la Almagra (Mula) y la Encarnación (Caravaca)n. II C.A.S.E., Albacete, 1946, págs. 300-302. 


\section{Tipos}

En general y como ya hemos aludido, el proceso de fabricación se hizo en caliente, batiendo el metal hasta formar una lámina delgada, de sección lenticular, triangular o rectangular con uno de los lados afilados, como es tradicional en el cuerpo de la hoja de la falcata real. En algunos casos e igualmente como en las piezas convencionales, la hoja tiene un borde afilado, el interno, y el otro biselado excepto su último tercio que está también afilado como en las falcatas evolucionadas (11).

Hemos seleccionado las piezas en un intento de clasificación tipológica provisional atendiendo al tipo de hoja, empuñadura y tratamiento de las mismas así como su aproximación morfológica a las piezas reales:

A) Prototipo. Corresponden a este grupo una serie de piezas de tamaño mayor con hoja plana y enmangue de sección rectangular (A1-A4) o redondeada (A2, A3, A5). Son notablemente aproximadas a las formas de las falcatas tardías, arco en forma de cabeza de caballo con síntesis de formas y guarda de cadenilla o alambre trenzado. La hoja igualmente está imitada de estos tipos, con filo interno y en el último tercio del lomo.

B) Prototipo sobre láminas sin retoques ni filos. Tipo similar al A, generalmente más simplificado. Su perímetro está sin afilar, en bisel simple sin retoque. Evoca los tipos de afiladera que aún en lá actualidad hallamos anexos a las piezas mayores, como en el caso de la pareja de cuchillitos afalcatados que acompañan a los goukra koukry tibetanos y a los cuchillos con ellos emparentados desde la India hasta Creta.

C) Falcata con hoja tipo falx, filo interior cóncavo. La empuñadura mantiene la forma de los tipos A y B, pero la hoja describe un arco más o menos abierto.

D) Falcata con hoja en ángulo y arco breve. Corresponde a una síntesis de las anteriores. El arco de la empuñadura es más corto. Se suavizan las formas de la garganta del arma hasta formar, en algunos casos (D4 y D6), una recta la línea interior de la empuñadura y la parte interior de la hoja. Formas simplificadas, no tienen filo en los casos conocidos.

E) Falcata con perfil en S. Formas cuidadas pero que denotan la obtención de nuevas líneas de diseño por parte de los artesanos saliéndose de la simple copia de las piezas mayores. La hoja va afilada en su parte inferior por ambos lados (E1, E2 y E3) o en el interior de la hoja y en el tercio inferior en doble filo (E4). En cuanto al enmangue, no se atiene a una forma fija.

F) Falcata con cavidad en el borde interior de la hoja. Parece realizar la característica principal de la falcata, su filo cóncavo interno, exagerando la línea. Pieza de filo acabado, más que por limitaciones técnicas esta forma está determinada por

(11) Cabré Herreros, M. E.: "Dos tipos genéricos de falcata hispánica». AEAA, X, págs. 200 y ss., Madrid, 1934

Nuestro agradecimiento a D. José Antonio Melgares Guerrero y D. Miguel Sannicolás por habernos facilitado el acceso a los materiales procedentes del Santuario de la Encarnación, actualmente depositados en el M. A. Provincial de Murcia y a D. Manuel García Ruiz, de Puebla de Don Fadrique por haberlo hecho con los procedentes de Almaciles. 
un diseño llamativo, con formas suaves y sinuosas (F2 y F3), hasta los perfiles de ángulos marcados (F4, F8 y F9).

G) Falcatas con lomo en ángulo. La ligera incurvación de la falcata pasa a ser un ángulo rectilíneo. En algunos casos las proporciones convencionales se conservan (G1 y G2) y pasan a tipos de diseño exagerado en el que parece haber una evolución del tipo (G3, G4, G5 y G6). Hay un predominio de las piezas no afiladas en el cuerpo de la hoja y con doble filo en su tercio inferior.

H) Formas simplificadas o tipos de aguja de hebilla. Emparentadas estilísticamente con las formas más simples, la hoja se hace rectilínea (H1 y H2) para dar lugar a un tipo formado por una lámina de sección rectangular o cuadrada, apuntada y con un arco en la parte superior, en muchos casos confeccionado de igual manera que en las piezas más complejas (H3 a H11) y en otras con el apéndice terminal hacia dentro (H12 a H21). Es a nuestro juicio la forma más simple y de más económica fabricación dentro del conjunto de exvotos conservados.

I) Falcatas con arco y guarda en forma de cuello y cabeza de cisne. Integran un grupo muy peculiar de clara raigambre fenicio púnica a nuestro parecer. Estilísticamente son formas que evocan los diseños en marfil y en bronce (las hojas de afeitar) del área de influencia referida.

J) Cuchillito con filo en la cara externa y enmangue en espiral. Pieza singular, parece más bien responder a un tipo caprichoso de forjado del enmangue, arrollando la espiga del puño en sentido contrario al habitual, lo que le da un aspecto extraño. La forma de enmangue en espiral es frecuente en las de tipo aguja de hebilla (H14 a H20).

K) Tipo falx. Corresponden a las formas ya publicadas por Tarradell y Font y por H. Fernández, procedentes de las necrópolis ibicencas. En este caso habríamos de excluir de su forma la evocación del ensis falcatus pero no hemos de desestimar el hecho de que los cuchillos afalcatados son complemento del ajuar guerrero y en muchos casos, en la vaina de la espada o falcata, van colocados uno o dos cuchillitos. En el tipo a que nos referimos es característica la amplitud de la mitad inferior de la hoja y queda atrofiado por lo general el arco de enmangue. Tienen un solo filo, el interno, el lomo es anguloso (K1), curvo (K3) y en algunos casos casi recto, evocando el tipo griego de kopis (K6).

L) Cuchillitos afalcatados. Como en el caso anterior son piezas en miniatura, de mucho menor tamaño que las piezas habituales del utillaje doméstico. Tienen filo único en la parte interna, tienen el enmangue recto y grueso figurando las cachas y forma una sola pieza con la hoja. 


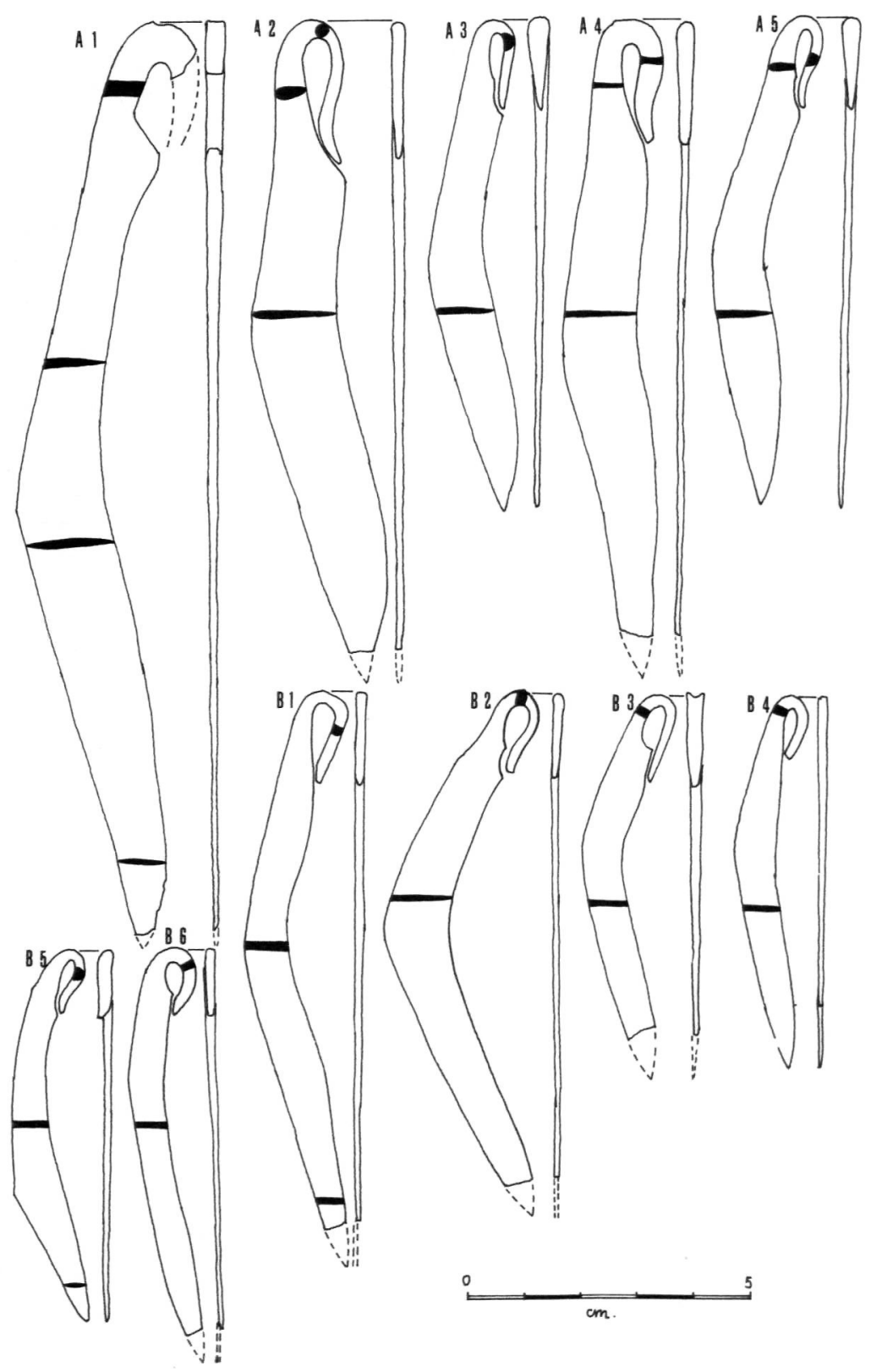

LÁM. I.-Pequeñas falcatas, A. 

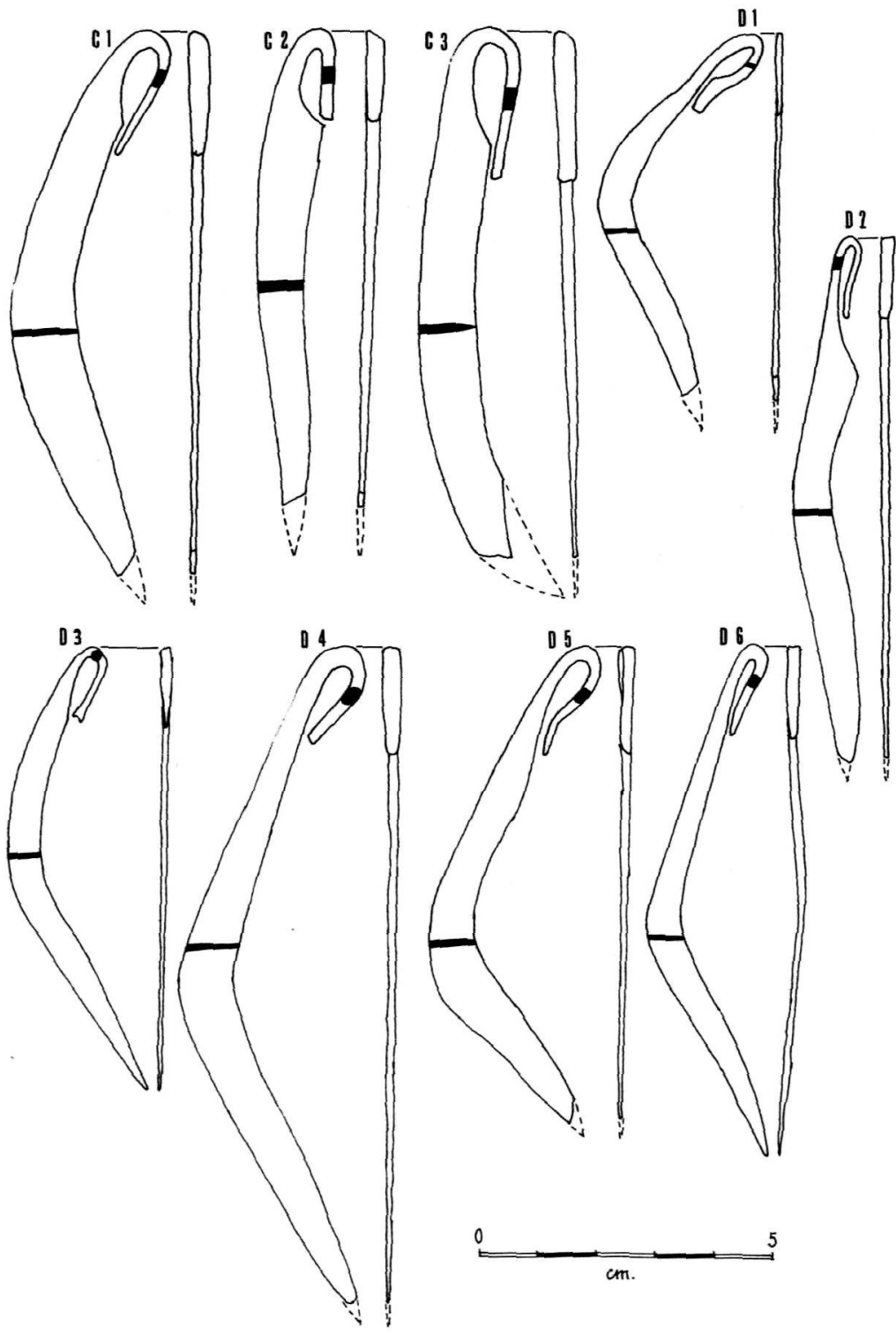

LÁM. II.-C, falcatas con filo interior cóncavo. D, con hoja en ángulo y arco breve. 


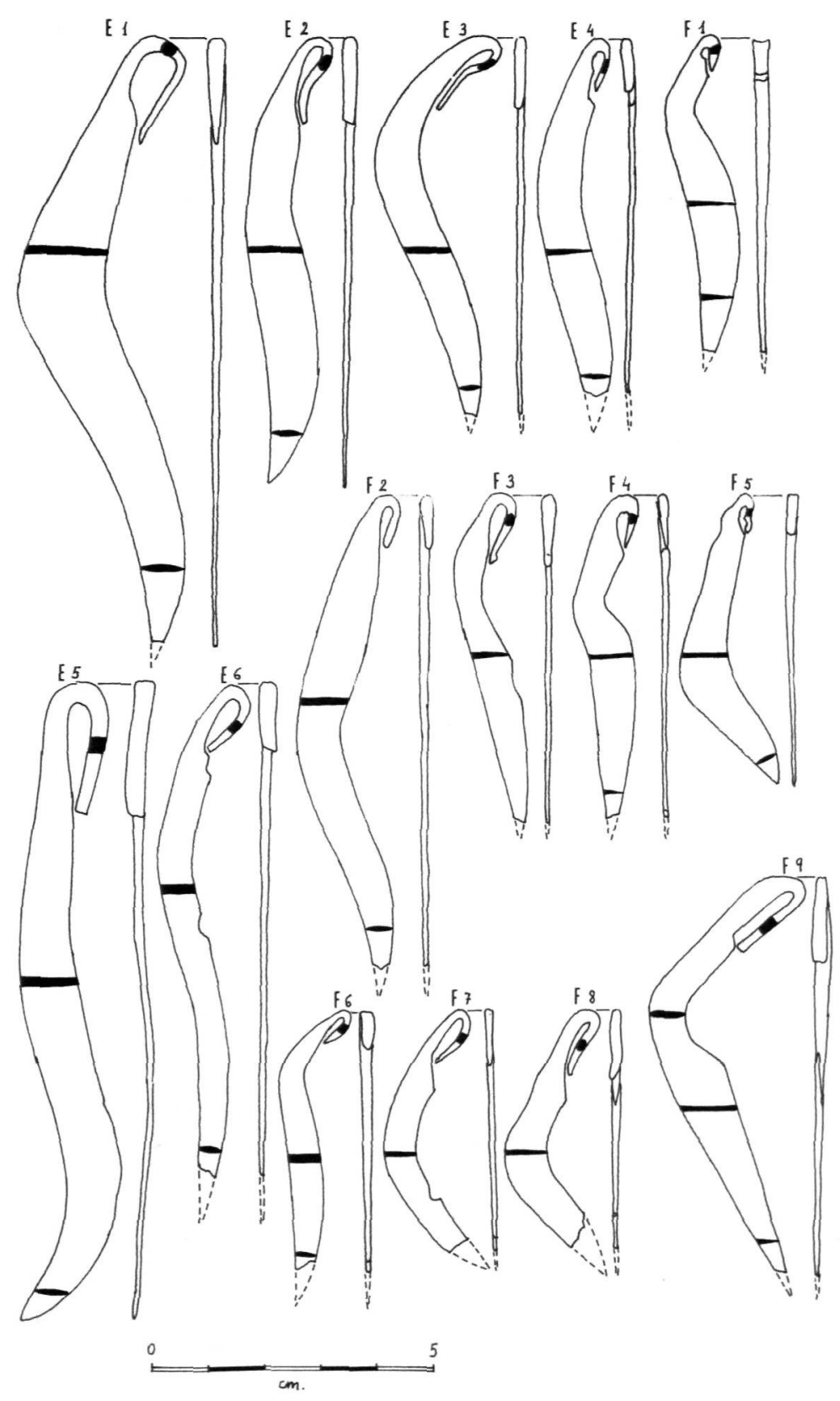

LÁM. III._E, falcata con perfil en S.F., falcata con concavidad en filo interior de la hoja. 

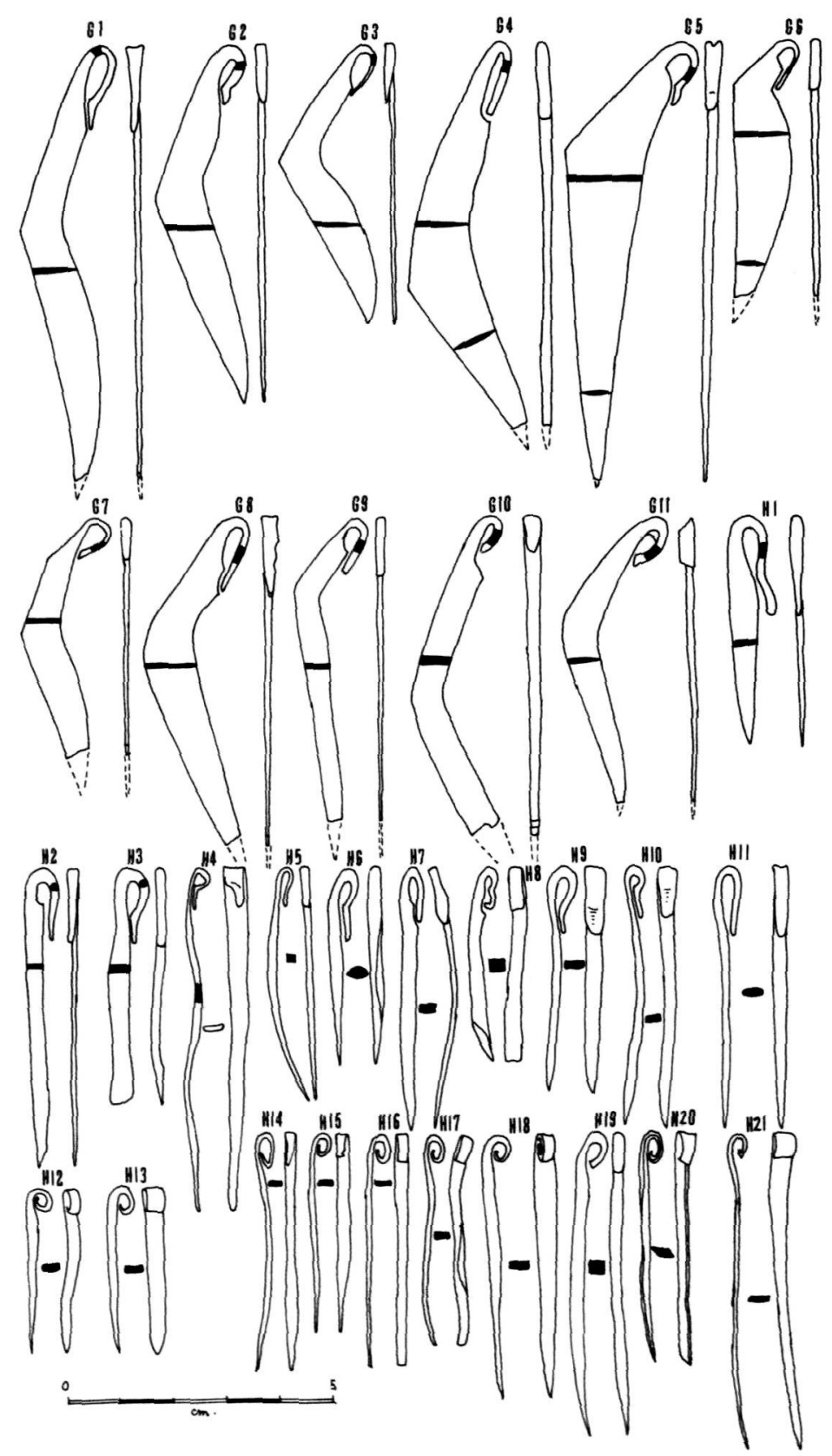

LÁM. IV.-G, falcata con lomo en ángulo. H, formas simplificadas o tipos de aguja de hebilla. 

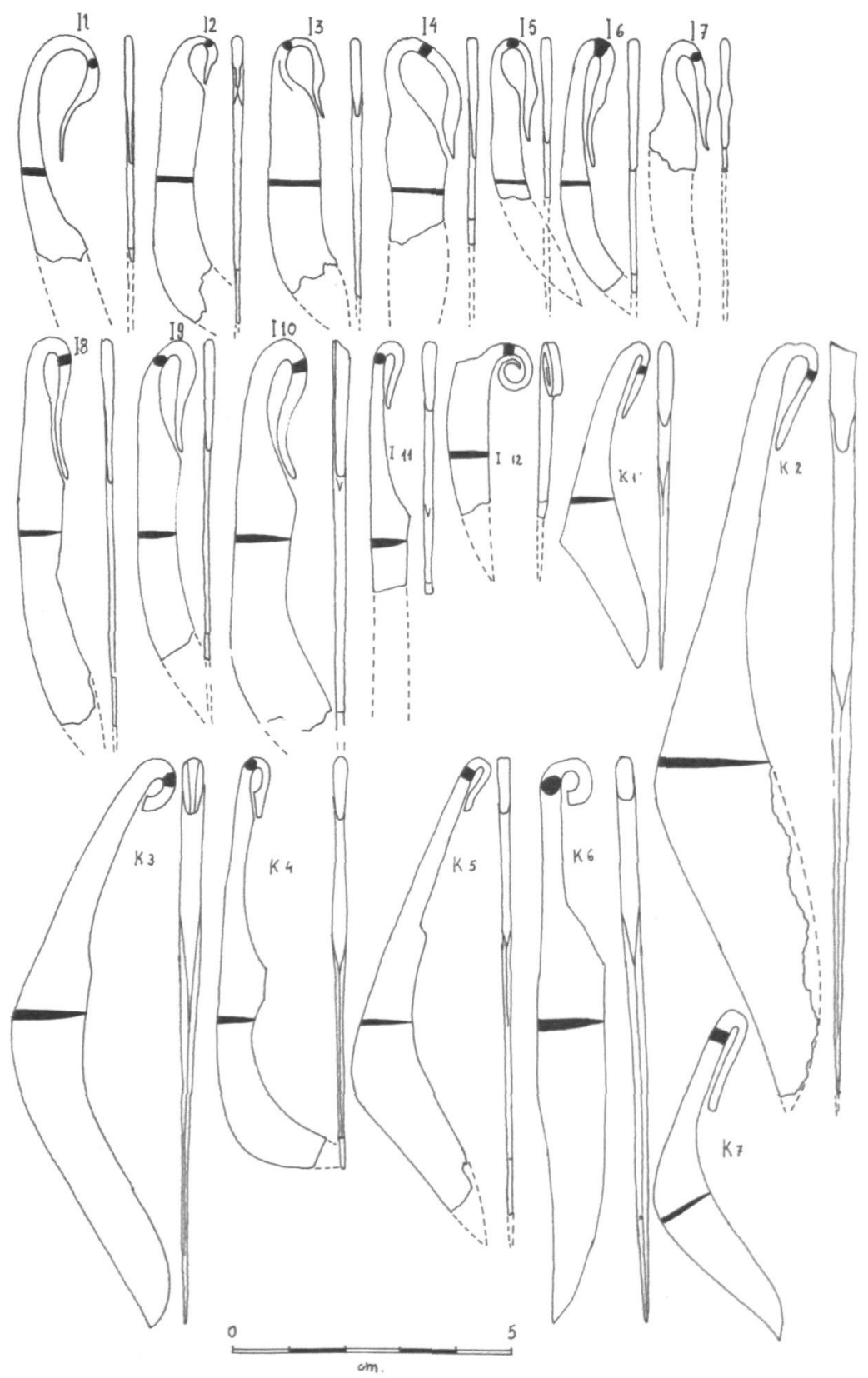

LÁM. V.-I, falcatas con arco y guarda en forma de cuello y cabeza de cisne. $\mathrm{J}$, cuchillito de enmangue en espiral. $\mathrm{K}$, tipo falx. 

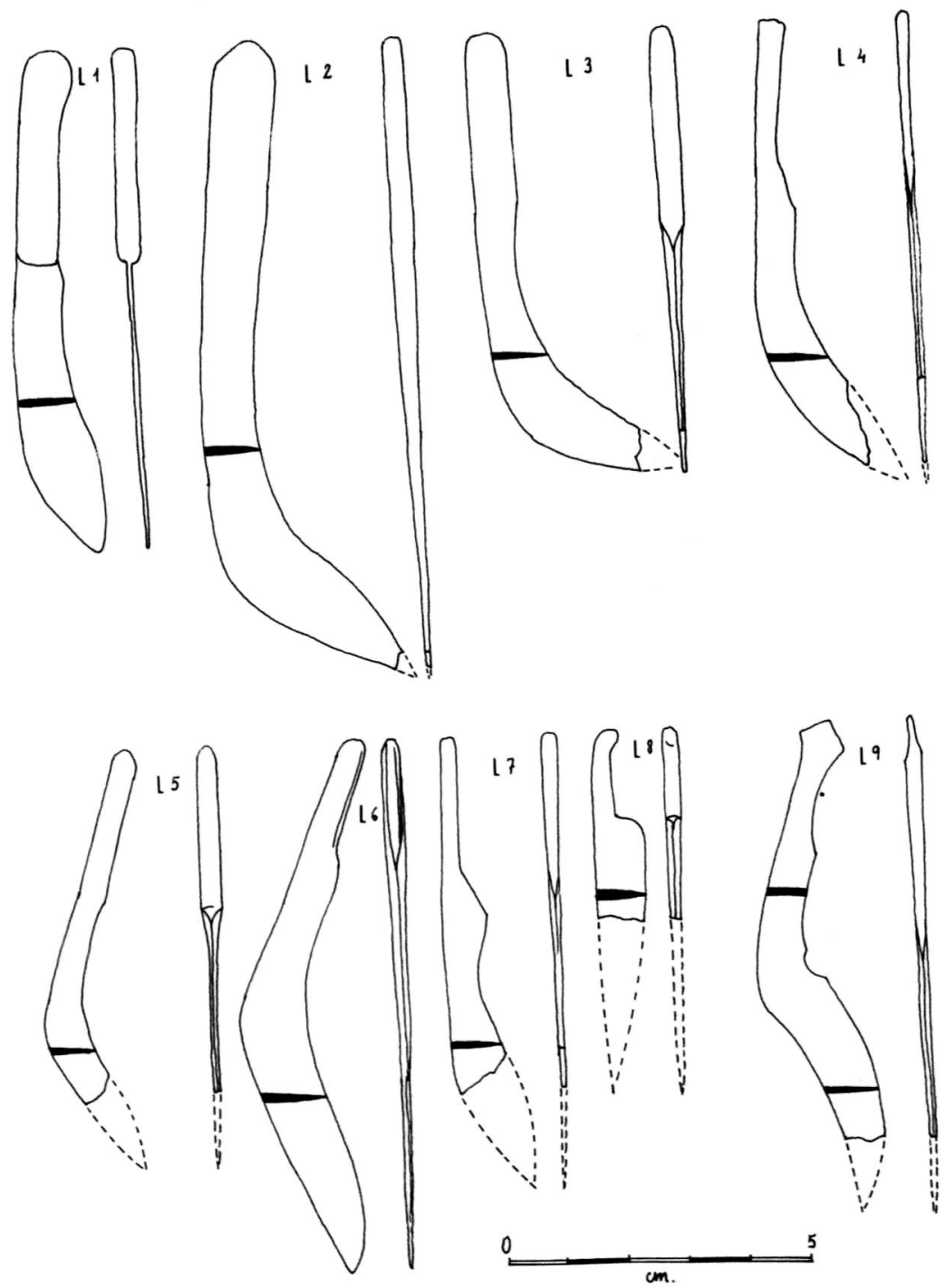

LÁM. VI.-L, cuchillitos afalcatados. 


\section{Conclusiones y cronología}

Tras esta precipitada síntesis de las piezas que hasta el momento hemos tenido oportunidad de contemplar, podemos aventurar una serie de puntualizaciones siempre a título provisional:

- Son piezas carentes de sentido funcional, no fueron utilizadas como herramientas cortantes (en muchos casos carecen de filo) y tampoco tiene sentido pensar que fuesen utilizadas como afiladeras.

- Los modelos no se repiten. No se hacen piezas intencionalmente iguales, lo cual hubiese costado poco al artesano. Muy al contrario, en muchos casos, hay una determinada intencionalidad de hacer un "diseño" nuevo y atrevido en el que se ve un claro sentido estilístico de síntesis de formas.

- Pese a las notables diferencias estilísticas, las piezas son coincidentes tipológicamente. Tanto las piezas ibicencas como las de los tres yacimientos surestinos a los que hacemos referencia no tienen variaciones substanciales. Este es un factor a tener en cuenta a la hora de observar analogías entre las distintas zonas geográficas y sus íntimos contactos como paso común desde el Mediterráneo a Turdetania, remontando los cauces fluviales.

- Parece evidente la función de exvoto de la mayoría de estas reproducciones de falcatas, si exceptuamos la pieza en forma de cuchillo afalcatado L1, única hallada en contexto de poblado.

- Influyen las formas de marcado sabor fenicio-púnico entre las que resalta el tipo I, con arcos de empuñadura en cuello de cisne, similares a los de las hojas de afeitar púnicas en bronce o los del tipo $\mathrm{K}$ similares a los cuchillitos ibicencos.

- Hay un factor fundamental, la exigencia de tipo técnico que hace que la pieza sea tosca y sumaria en virtud a su pequeño tamaño. Así hay piezas de mala terminación - sin afilar ni retocar- y formas muy simples - tipos en forma de aguja de hebilla.

- Están asociadas a lugares de culto, pudiéndose relacionar con otras piezas metálicas ya conocidas como lanzas y sobre todo exvotos de guerreros de bronce con sus armas, elementos consubstanciales a los grandes santuarios ibéricos surestinos.

- La reproducción en pequeño y a modo de exvoto de la falcata puede simbolizar la entrega del guerrero a la divinidad.

La personificación del arma evita la entrega de exvotos de figuras, más onerosa para el donante.

Habría un claro paralelismo de estos ritos de exvoto con los de enterramiento. El valor intrínseco de los exvotos de bronce puede apoyar esta hipótesis de trabajo ya que dichas piezas debieron ser de difícil adquisición por parte de los miembros más modestos de las comunidades ibéricas.

Queda pues la posibilidad de que sean un símbolo cultual de los valiosos exvotos de guerrero en bronce pleno.

En cuanto a la cronología, dada la considerable cantidad de piezas presentes en algunos yacimientos, nos inclinamos a pensar que la mayoría corresponden a 
los momentos en que se "arma" a los auxilia a lo largo del s. II y principio del s. I a. C., hecho que sería confirmado por la mayoría de los restos cerámicos hallados en los contextos, encuadrables entre finales del s. III a. C. y la época previa a la fase imperial. La aparición de cerámicas más antiguas, algunos fragmentos de cerámicas áticas de figuras rojas en los tres yacimientos citados y los testimonios arqueológicos posteriores hacen estas fechas provisionales dado que, por otra parte, hay constancia de una dilatada pervivencia de los santuarios ibéricos hasta plena época imperial. 